\title{
Contratos públicos e o seu gerenciamento por parte do chefe do executivo municipal
}

\author{
Public contracts and their management by the head of the municipal executive \\ Contratos públicos y su gestión por el jefe del ejecutivo municipal
}

Recebido: 18/07/2021 | Revisado: 16/07/2021 | Aceito: 01/08/2021 | Publicado: 06/08/2021

\author{
Ricardo Ovídio de Oliveira Lima \\ ORCID: https://orcid.org/0000-0002-1645-7537 \\ Faculdade São Vicente, Brasil \\ Universidade Potiguar, Brasil \\ E-mail: ricardooliveira-adv@hotmail.com \\ Thalita Kelle Pires Beserra \\ ORCID: https://orcid.org/0000-0003-2693-8702 \\ Faculdade São Vicente, Brasil \\ Universidade Potiguar, Brasil \\ E-mail: tpiresb@gmail.com \\ Nilton Soares Formiga \\ ORCID: https://orcid.org/0000-0003-4907-9736 \\ Universidade Potiguar, Brasil \\ E-mail: nsformiga@yahoo.com
}

\begin{abstract}
Resumo
O presente artigo tem por finalidade analisar o comportamento da administração pública municipal a partir da atuação do gestor de contratos, observado o gerenciamento e fiscalização dos contratos administrativos públicos, verificando os comprometimentos que podem afetar a administração quando ocorre má gerência das peças contratuais pelo chefe do executivo. Para atingir esse objetivo, o presente estudo utilizou-se de literaturas, leis e julgados que tratam sobre a gestão pública e contratual, onde os autores evidenciaram também as peculiaridades da gestão de contratos no âmbito do poder público, demonstrando quais responsabilizações podem ocorrer ao chefe do executivo caso incida em desobediência às normas jurídicas que envolvem o serviço público e, em específico, a gestão de contratos. A legislação e normativas nem sempre são suficientes para que a execução contratual se realize em sua forma plena, uma vez que a tecnicidade e familiaridade com o objeto gerido nem sempre existem, e em existindo correm-se riscos de dano à máquina pública devido às omissões ou condutas antijurídicas do agente, caso não atue de forma proba.
\end{abstract}

Palavras-chave: Administração municipal; Gestão de contratos; Responsabilizações.

\begin{abstract}
The present article is to analyze the behavior of the municipal public administration from the role of the contract manager, observing the management and inspection of public administrative contracts, verifying the commitments that can affect the administration when there is bad management of contractual parts by the head executive and by civil servants who are not technically prepared. To achieve this goal, this study used literature, laws and judgments that deal with public and contractual management, where the authors also highlighted the peculiarities of contract management within the public power, demonstrating which accountability can occur to public servants. involved in the event that they disobey the legal norms that involve the public service and, specifically, the management of contracts. Thus, it was observed that public servants are condemned for poor inspection of contracts and for causing damage to the population. The legislation and regulations are not always sufficient for the contractual execution to take place in its full form, since the technicality and familiarity with the managed object do not always exist, and if they exist, there are risks of damage to the public machinery due to omissions or the agent's unlawful conduct, if he/she does not act in a righteous manner.
\end{abstract}

Keywords: Municipal administration; Contract management; Accountability.

\section{Resumen}

El propósito de este artículo es analizar el comportamiento de la administración pública municipal desde el rol de contratista, observando la gestión y supervisión de los contratos públicos administrativos, verificando los compromisos que pueden afectar a la administración cuando existe una mala gestión de las partes contractuales por parte del jefe ejecutivo y funcionarios públicos que no estén preparados técnicamente. Para lograr este objetivo, este estudio utilizó literatura, leyes y sentencias que tratan de la gestión pública y contractual, donde los autores también destacaron las peculiaridades de la gestión de contratos dentro del poder público, demostrando qué rendición de cuentas puede ocurrir a los servidores públicos involucrados en el evento que desobedecen las normas legales que involucran el servicio público y, específicamente, la gestión de contratos. Así, se observó que los servidores públicos son condenados por mala fiscalización de los contratos y por causar daños a la población. La legislación y la 
normativa no siempre son suficientes para que la ejecución contractual se lleve a cabo en su forma íntegra, ya que no siempre existe el tecnicismo y familiaridad con el objeto gestionado, y de existir, existen riesgos de daño a la maquinaria pública por omisiones o conducta ilícita del agente, si no actúa en forma probatoria.

Palabras clave: Administración municipal; Gestión de contratos; Responsabilidad.

\section{Introdução}

A Lei n. 14.133/21, em seu art. 117, prevê a necessidade de um servidor público especialmente designado para acompanhar e fiscalizar os contratos celebrados pela Administração Pública. Sabe-se que nos órgãos públicos existe pessoal tecnicamente preparado para exercer a atribuição em comento, bem como existem casos em que a Administração Pública não possui pessoal adequadamente capacitado, o que leva à necessidade de se promover cursos e treinamentos para tais, muito embora muitas das vezes tal circunstância não seja possível.

Para uma relação contratual eficaz entre a Administração Pública e o contratado, é de suma importância que exista uma gestão de contratos eficiente, a fim de que o interesse público prospere. Em sendo assim, surge o questionamento: quais as consequências e/ou danos para a Administração Pública nos casos de ingerência contratual?

Sendo assim, pretende-se neste artigo compreender, a partir das legislações vigentes, a dinâmica e estrutura dos tribunais e suas decisões acerca da falta de fiscalização nos contratos públicos, e em encontrando desídias, quais as punições estabelecidas para tanto.

Também, é interesse do artigo, compreender os prejuízos que sobrevêm à população em situações em que o objeto contratual em tese deveria ser para seu atendimento, mas que por condutas ilegais dos agentes, não fora possível. A problemática encontra-se válida, haja vista os crescentes casos de descobertas de desvio de recursos públicos através de contratos fraudados com grandes empresas, onde a polícia federal, ministério público e tribunais de contas têm atuado de forma diligente nas contas públicas dos órgãos da Administração, servindo de alerta para todos os servidores vinculados.

O bom trato com a coisa pública, gerindo de forma profissional e impessoal é imprescindível quando se entende que a Administração atualmente precisa em sua gestão ser muito mais gerencial do que patrimonialista ou burocrática. Entender que a entrega da gestão de contrato a um servidor que de fato esteja preparado é de suma importância para que se preserve o erário e a responsabilidade para com a finalidade coletiva.

\section{Metodologia}

Para a confecção desse artigo foi realizada uma pesquisa bibliográfica em textos legais, doutrina, jurisprudência e tantos outros documentos que foram úteis e necessários para a abordagem do tema proposto. O método para o desenvolvimento será teórico e, para o delineamento das conclusões, empregou-se a síntese do pesquisado, de forma a embasar a tese enunciada no objetivo geral do trabalho, assim a natureza qualitativa da pesquisa se fez existir.

De acordo com Minayo (2016, p. 21) a pesquisa qualitativa responde a questões muito particulares. Ela se preocupa, nas ciências sociais, com um nível de realidade que não pode ser quantificado. Assim, a pesquisa qualitativa é uma atividade sistemática, orientada à compreensão em profundidade de fenômenos educativos e sociais, à transformação de práticas e cenários educativos, em processo ativo, sistemático e rigoroso de indagação dirigida, se tomam decisões sobre o que é pesquisado quando se está no campo de estudo (Esteban, 2017).

Quanto ao uso da pesquisa bibliográfica, Gil (2019) que esta se constitui a toda produção publicada sobre o referido tema. E a pesquisa documental encontra-se apoiada Ludke; André (2013) que aludem que o uso de documentos constituiu-se uma técnica valiosa, complementam as informações obtidas por outras técnicas, além de constituírem uma fonte rica que dá mais estabilidade e confiabilidade aos resultados da pesquisa. 


\section{Resultados e Discussão}

\subsection{Competências Municipais e a Responsabilidade do Chefe do Executivo}

A composição do Governo Municipal é refletida pela gestão da prefeitura e câmara de vereadores. Neste artigo teremos por foco as ações de gerenciamento contratual desenvolvidas pelo executivo.

Os municípios possuem autonomia político-administrativa e financeira, razão esta que lhe imputa capacidade de empregar ações de desenvolvimento econômico e social. De acordo com Mello (2005, p.94): “administrar é prover aos interesses públicos, assim caracterizados em lei, fazendo-o na conformidade dos meios e formas nela estabelecidos ou particularizados segundo suas disposições”. Deste modo, a competência do município está enraizada no que lhe cabe enquanto pessoa jurídica de direito público interno, de acordo com a sua autonomia estabelecida na Constituição da República Federativa do Brasil de 1988 - CRFB/88. Diante disso, o município deve obedecer aos preceitos constitucionais no que tange a instituição de tributos e arrecadação. No que corresponde à organização das atividades e serviços prestados pelo ente municipal, este deve fazê-lo de forma que atenda satisfatoriamente ao interesse público e bem-estar social, segundo as necessidades do município e sua territorialidade, seguindo também as regras constitucionais (Manual Do Prefeito, 2009).

Ainda em sede de competências municipais, seu rol é estabelecido nos arts. 23 e 30 da CRFB/88, onde o primeiro trata das competências comuns entre a União, Estados, Distrito Federal e municípios, e o segundo das competências exclusivas do município. Segundo Meirelles (1995), no que tange ao poder executivo municipal, este é representando pela figura pública do prefeito, o qual detém e empreende as atividades de gestão da administração municipal.

Em razão da competência constitucional específica conferida ao município, é essencial que este tenha um conjunto de leis municipais atualizadas, delimitando, especificando e organizando a estrutura e atribuições dos órgãos administrativos com o objetivo de melhor administrar e planejar as ações do governo municipal, na aplicação adequada do erário e atendimento à finalidade do interesse social.

De outra sorte, o art. 37 da CRFB/88 estabelece os princípios constitucionais, obrigando a Administração como um todo à sua obediência. Dentre tais princípios, destacamos o da legalidade, o qual sujeita o administrador público ao estrito cumprimento das leis e atendimento ao bem comum.

Ainda na seara dos princípios, destaca-se em especial o da eficiência que aduz à profissionalização da Administração Pública através dos seus servidores. Nesta senda, é salutar perceber a atividade de um gestor de contratos como algo intrinsecamente ligada ao interesse público, vez que este, além do gerenciamento, promove também a fiscalização do erário e sua correta aplicação por meio da relação contratual estabelecida em torno de um objeto que a Administração necessita que um terceiro execute ou forneça.

Em relação ao papel que o gestor municipal desempenha quando designa obrigações aos seus subordinados, transmitindo-lhes responsabilidade sobre determinadas ações, o prefeito deve alinhar junto à sua obediência ao princípio da legalidade, o atendimento também à supremacia do interesse público, vez que este dará resultados positivos no desempenho e alcance do serviço público, de forma satisfatória. Ademais, comandar essas ações está intrinsecamente ligada a:

[...] orientar, verbalmente ou por meio de decretos, instruções, ordens de serviço, portarias e outros atos administrativos. O(A) Prefeito(a), como responsável final pelo que acontece na Administração, dirige toda a máquina da Prefeitura, com o auxílio da sua equipe de secretários e dos responsáveis pelos diversos setores. Não obstante, vale lembrar que o Prefeito é a autoridade máxima na direção da Administração Municipal e, por isso, detém a responsabilidade políticoadministrativa final pelos atos de sua Administração, tanto dos que praticou pessoalmente como dos que foram praticados pelos seus subordinados. (Manual Do Prefeito, 2009, p. 39, grifo nosso).

Analisando o que foi citado acima, a responsabilidade sobre aqueles atos de ingerência que forem praticados na gestão de um contrato podem ser conferidos também ao chefe do executivo, na medida de que é este quem indica através de portaria o 
subordinado que gerenciará o instrumento contratual.

Para que a máquina administrativa siga todo o procedimento de forma correta é importante que seja descentralizada ou delegadas atividades do gestor municipal. Para tanto, é necessário que se tenha cautela nos atos de nomeação e consequentes deliberações estabelecendo delimitação de atuação e de responsabilidades para os serviços ou atividades administrativas, de forma a contribuir com o trabalho do gestor municipal, o deixando livre para solucionar outras questões de maior complexidade referentes à administração municipal.

Com o objetivo de manter o controle sobre as atividades que forem delegadas, evitando que responsabilidades de ingerências recaiam sobre si, cabe ao chefe do executivo definir reuniões periódicas, relatórios, inspeções e outros atos que justifiquem as decisões que os subordinados tomarem.

Por força de Lei, algumas responsabilizações serão impostas ao gestor municipal em caso de práticas inadequadas. Tais práticas estão consubstanciadas em responsabilizações administrativa, cível e criminal. Assim, em relação aos crimes de responsabilidade, deve o gestor não incidir nas disposições previstas no $\$ 2^{\circ}$, do art.29-A, da CRFB/88; devendo observar o Decreto-lei n. 201/67, para que não caia em desobediência. Em relação aos crimes funcionais, estes estão definidos nos arts. 312 a 326 e 359-A a H, do código penal brasileiro. Também há previsão de crime de abuso de autoridade, com base na Lei n. 4.898/65. Além do mais, o chefe do executivo municipal ao cometer infrações político-administrativas, poderá sofrer punição com perda de mandato; as práticas que reverberam tal conduta estão previstas em lei orgânica municipal ou lei especial.

\subsection{Contratos Públicos e seu Gerenciamento}

Na Administração Pública o gerenciamento de contratos é basilar para o atendimento adequado dos serviços prestados pelo município ou aquisições com vistas à melhor consecução das atividades administrativas de um órgão e consequentemente assistência ao público atendido, a exemplo de: aquisição de maquinário para um hospital público a fim de tornar mais excelente o serviço médico prestado.

De acordo com Leite et al. (2010) os processos que envolvem contratualização na administração pública devem ser realizados em etapas, que: 1 - definam as metas e serviços a serem contratados; 2 - elaborem o plano de gerenciamento; 3 formalizem e executem o contrato; e 4 - acompanhem e avaliem a execução.

Assim, o processo de construção de um contrato não ocorre somente após a licitação e seus trâmites de finalização e fechamento. Muito pelo contrário, a construção se inicia na deflagração do processo administrativo que gerará a futura peça contratual. Assim, em conjunto com o procedimento de formação de uma solicitação de despesa com as devidas cotações para se chegar a um valor estimado de contratação, surge a questão do que terá que ser convencionado em contrato; razão está que condiciona o termo de referência e edital de licitação a preverem quais serão as obrigações contratuais a serem geradas após a contratualização entre o fornecedor/prestador do serviço e o órgão público.

A Lei n. 14.133/21 traz a definição sobre contrato, a qual compreende um conjunto de direitos e obrigações que a administração pública e o particular celebram entre si, devendo haver um acordo de vontades. Tal pacto sempre terá que ter por finalidade atingir o interesse social, tendo em vista que se lida diretamente com o erário e com a coisa pública.

Corroborando ainda com o conceito de contrato, a melhor doutrina diz que este é um “[...] ajuste que a Administração, nessa qualidade, celebra com pessoas físicas ou jurídicas, públicas ou privadas, para a consecução de fins públicos, segundo regime jurídico de direito público" (DI PIETRO, 2014, p. 263). De outra sorte, o art. 104, da Lei n. 11.133/21 traz o rol incidente quanto ao poder dever da Administração Pública em gerir e fiscalizar os contratos administrativos.

Ademais, em seu art. 117, a Lei supracitada determina que a execução do contrato deve receber a fiscalização e acompanhamento de um representante (gestor do contrato) especialmente designado pela Administração. Insta salientar que, o contrato público se diferenciará dos privados pelo fato de conter cláusulas chamadas exorbitantes, as quais colocam a 
Administração em supremacia ao contratado, de forma a preservar a finalidade pública.

Nesta senda, é importante abrir espaço para que se diferencie a figura do gestor e do fiscal de contratos, tendo em vista que as atribuições são diferentes, embora muitas vezes por questões de planejamento a Administração entenda por bem designar um servidor que acumule ambas as atribuições. Destaca-se:

GESTOR DO CONTRATO: servidor formalmente designado pela DGI para acompanhar e coordenar as atividades dos fiscais e receber definitivamente o serviço (ato que concretiza o ateste), após análise dos relatórios apresentados pela fiscalização técnica e administrativa. É responsável também pelos procedimentos iniciais ou preparatórios, a fim de dar encaminhamento ao setor de contratos dos atos relativos a: prorrogações, alterações, reequilíbrio, pagamentos, eventuais sanções e extinção do contrato. FISCAL TÉCNICO DO CONTRATO: servidor indicado pela Área Demandante Dos Serviços, formalmente designado pela Diretoria de Gestão Interna (DGI), para acompanhar e fiscalizar a execução dos serviços terceirizados, conferir a conformidade e a qualidade dos serviços prestados, realizando o recebimento provisório dos serviços; FISCAL ADMINISTRATIVO DO CONTRATO: servidor formalmente designado pela DGI para acompanhar a execução dos serviços terceirizados, no que se refere ao acompanhamento do cumprimento das obrigações trabalhistas, previdenciárias e fiscais pela contratada, bem como receber provisoriamente o serviço. FISCAL SETORIAL: servidor formalmente designado pela Diretoria de Gestão Interna (DGI) para acompanhar a execução do contrato nos aspectos técnicos ou administrativos, quando a prestação dos serviços ocorrer concomitantemente em setores distintos [...] (ENAP, 2018, p. 5).

Seguindo o exposto, pode-se compreender que as atribuições que cercam os gestores e fiscais de contratos são das mais variadas, implicando diretamente na obrigatoriedade da prestação de um serviço público de qualidade, não dando margem para que haja desídias que comprometam a finalidade contratual, devendo as situações acima descritas serem perseguidas com diligência, observando ainda os princípios da probidade e boa-fé.

É relevante apresentar nessas linhas o que diz a Instrução Normativa n. 05/2017 do então Ministério do Planejamento Desenvolvimento e Gestão (atual Ministério da Economia, conforme medida provisória n. 870/2019) acerca do gerenciamento e fiscalização do contrato. In verbis:

Art. 40. [...] $3^{\circ}$ As atividades de gestão e fiscalização da execução contratual devem ser realizadas de forma preventiva, rotineira e sistemática, podendo ser exercidas por servidores, equipe de fiscalização ou único servidor, desde que, no exercício dessas atribuições, fique assegurada a distinção dessas atividades e, em razão do volume de trabalho, não comprometa o desempenho de todas as ações relacionadas à Gestão do Contrato (p.1, grifo nosso).

Nesse sentido, quanto às atividades de gestão e fiscalização, entende-se que aquela está ligada à práxis administrativa do contrato, enquanto esta compreende o cuidado pontual para com o acompanhamento do cumprimento das cláusulas convencionadas de forma a gerar resultados quantitativamente e qualitativamente positivos.

A instrução normativa acima citada elucida como a gestão e fiscalização de um contrato público deve ser realizada. O seu art. 47 assim dispõe:

A execução dos contratos deverá ser acompanhada e fiscalizada por meio de instrumentos de controle que compreendam a mensuração dos seguintes aspectos, quando for o caso:

I - os resultados alcançados em relação ao contratado, com a verificação dos prazos de execução e da qualidade demandada;

II - os recursos humanos empregados em função da quantidade e da formação profissional exigidas;

III - a qualidade e quantidade dos recursos materiais utilizados;

IV - a adequação dos serviços prestados à rotina de execução estabelecida;

$\mathrm{V}$ - o cumprimento das demais obrigações decorrentes do contrato; e

VI - a satisfação do público usuário.

$\S 1^{\circ}$ Deve ser estabelecido, desde o início da prestação dos serviços, mecanismo de controle da utilização dos materiais empregados nos contratos, para efeito de acompanhamento da execução do objeto bem como para subsidiar a estimativa para as futuras contratações.

$\S 2^{\circ}$ A conformidade do material a ser utilizado na execução dos serviços deverá ser verificada juntamente com o 
documento da contratada que contenha a relação detalhada destes, de acordo com o estabelecido no contrato, informando as respectivas quantidades e especificações técnicas, tais como marca, qualidade e forma de uso. (p.1).

A Lei de licitações n. 14.133/2021 traz em seu artigo 337-E ao 337-P as responsabilizações e punições ao gestor público no caso de contratações indevidas e direcionamento do objeto da licitação, dentre outros, trazendo os delitos ligados também ao gestor do contrato nos casos de negligências contratuais geradas na conduta dolosa e/ou culposa do ato. Por ser o rol extenso, citamos aqui a exemplo o art. 337-H que sustenta como crime a obtenção de vantagens indevidas por meio dos contratos, sendo tal conduta punida com pena de detenção, de dois a quatro anos, e multa.

Meirelles (1995) lecionou que, ocorrendo a inexecução ou inadimplência do contrato há por seguinte o descumprimento de suas cláusulas, seja no todo ou em parte, onde tal situação contratual pode ocorrer por conduta do gestor através de atitudes de ação ou omissão, culposa ou sem culpa, de forma a caracterizar o retardamento ou o descumprimento parcial ou integral do que fora inicialmente ajustado, podendo ainda tais situações ensejarem em responsabilidades para o inadimplente, gerando em último caso a rescisão do contrato.

No que atine à responsabilidade objetiva e subjetiva do gestor público em relação aos seus atos, Carvalho Filho (2012, p. 45) destaca que o "corolário importante do poder-dever de agir é a situação de ilegalidade de que se reveste a inércia do administrador: na medida em que lhe incumbe conduta comissiva, a omissão (conduta omissiva) haverá de configurar-se como ilegal".

Com isso, deve-se entender que muito embora determinado administrador público possa delegar a um servidor a gestão de um contrato, tal delegação não afasta o dever de agir com fiscalização sobre o ato que fora entre gue ao subordinado. Corroborando com esse entendimento, o douto Marçal Justen Filho (2010, p.909) leciona que:

[...] não bastam os esforços e a boa vontade do sujeito. É imperioso que tais esforços se traduzam na efetiva obtenção de resultados satisfatórios. Não se aplica nas funções administrativas o modelo da atuação do bonus pater familia. O exercente da função administrativa está obrigado a cumprir não apenas os padrões médios de diligência. Tem o dever de atender às exigências mais rigorosas, com a observância da mais elevada especialização. Somente se legitima a não obtenção do melhor resultado quando estiver rigorosamente fora da previsibilidade do agente estatal. Para usar palavras claras, ainda que pouco técnicas: a tolice configura infração aos deveres do agente administrativo quando provoca lesão a interesse alheio.

Do citado compreende-se que há uma cobrança ao Administrador para que não caia em inércia, mas se digne em comprometimento e a estar vigilante quanto às suas designações, uma vez que havendo ingerência, o dano não abrangerá apenas o gestor do contrato ou gestor municipal, mas também toda uma coletividade.

É necessário trazer à baila conceituações acerca de responsabilidade objetiva e subjetiva do administrador/gestor de contratos. Juridicamente, responsabilidade é o resultado gerado a partir da realização de um ato ilícito. Deste modo, a subjetiva acontece quando o ato ilícito foi cometido por culpa, ou seja, sem a intenção de fazê-lo; o que difere da objetiva, a qual se exterioriza pelo fato de realizar a ilicitude de forma consciente e com desejo de fazê-la; em ambos os casos demonstrando-se o nexo causal e a conduta do agente. Importante destacar que, em qualquer hipótese de responsabilidade, deverá ocorrer a obrigação de reparar o dano (Tribunal de Contas da União - TCU, 2013).

De acordo com o TCU (2013, p.11), a responsabilidade nos processos dos tribunais de contas se origina de conduta comissiva ou omissiva do agente, dolosa ou culposa, cujo resultado seja a violação dos deveres impostos pelo regime de direito público aplicável àqueles que administram recursos do Estado ou ainda aos que, sem deter essa condição, causarem prejuízo aos cofres públicos.

Desta forma, percebe-se que em quaisquer aspectos de responsabilidades, estes deverão ser apurados e julgados pelo Controle Externo, abrangendo sua fiscalização sobre todas as condutas do agente público, observando se houve conduta 
antijurídica no trato com a coisa pública.

Assim, trazendo para o campo da gestão contratual, pode-se concluir que, havendo ingerências administrativas na fiscalização do contrato e ocorrendo a malversação do dinheiro público, quando, por exemplo, sobrevém o atesto de forma culposa ou dolosa de uma nota fiscal superfaturada do objeto do contrato, tais irregularidades deverão ser apuradas, tomandose as devidas providências para com o agente (s) causador (es) do dano. Ademais, o gestor deve ter sempre em mente o entendimento de que ele deve cumprir estritamente o que a lei determinar, uma vez que a sua não observância é um indicativo de negligência.

Cabem aqui também algumas observações acerca de culpa in vigilando e culpa in eligendo, vez que tais institutos estão intrinsecamente ligados à conduta de agentes na gestão do executivo e consequentes deliberações quanto à determinadas atividades gerenciais. Em sendo assim, o TCU (2013) conceitua a culpa in vigilando como decorrente da não observância ou falta de zelo para com as ações desenvolvidas a quem foi delegada uma atividade; nesse sentido, existem diversos julgados do Tribunal de Contas, onde gestores foram responsabilizados por tal conduta, sofrendo como punições a imputação de débito e aplicação de multa: Acórdãos n. 698/2002, n. 699/2002, n. 963/2006, ligados a 1ª Câmara, e n. 730/2004 e 1.432/2006, ambos do Plenário.

A culpa in eligendo, corresponde à má escolha da pessoa a quem será delegada determinada atividade. Ou seja, existe um ou alguns atos a serem desenvolvidos, a exemplo da gestão de contratos, e o chefe do executivo erra na escolha ao colocar uma pessoa que não é tecnicamente preparada nem tampouco possui afinidade ou manejo para com a questão a ser gerenciada, o que faz surgir a culpa in eligendo.

Nesta senda, o TCU (2013) diz que havendo a escolha de subordinados sem experiência e despreparados para a realização de alguma atividade, pode se desdobrar na responsabilização daquele que o indicou, assumindo assim os riscos da má escolha. À vista disso, tem-se o julgamento da Ação Civil Pública, proc. N. 47.401/98, realizado pelo TJ do Distrito Federal, através da Quinta Turma Cível, apud TCU (2013) que decidiu acerca da questão em comento:

Presidente de Associação que delega a coordenação da entidade a terceiro, mesmo ao amparo de norma estatutária, responde solidariamente por danos que este causa à entidade, desviando para fins particulares valores que ela recebeu para a consecução de seus fins sociais. Trata-se de culpa in eligendo et in vigilando, que prescinde da demonstração do dolo do preponente em coadjuvar as atividades ilícitas de seu preposto. (p.1)

Do exposto, compreende-se que há uma ligação direta entre a forma que será gerido um contrato, desde a indicação do subordinado responsável, perpassando pela fiscalização de seus atos até o controle sobre o gerenciamento da atividade designada, devendo ainda observar se não há omissão, culpa ou dolo na conduta que venha a prejudicar a Administração Pública.

\section{Considerações Finais}

O presente artigo buscou analisar a gestão de contratos no âmbito do poder público municipal, especialmente por parte do chefe do executivo. Sabe-se que cada contrato e gestão municipal têm suas peculiaridades na condução dos objetivos para atingir a finalidade perseguida na contratação de um serviço. Porém, é necessário um olhar técnico para que torne a referida atividade de gestão seja de fato profissional, não entregando-a como algo qualquer onde só se deva ser controlado prazo de vigência com seu início e término. Administrar um contrato vai além da simples conferência citada. É atender os interesses comunitários que o cercam, é ver a política pública sendo realizada, e é perceber o retorno que isto dará à gestão municipal como um todo. 
Research, Society and Development, v. 10, n. 10, e115101018382, 2021

(CC BY 4.0) | ISSN 2525-3409 | DOI: http://dx.doi.org/10.33448/rsd-v10i10.18382

A posterior analise da efetiva aplicação da nova lei, baseará a continuação desse estudo, de forma a ver quais as novas aplicações foram efetivadas e as que não tiveram proveito efetivo.

\section{Referências}

Brasil (2013). Responsabilização de Agentes Segundo a Jurisprudência do TCU - Uma Abordagem a partir de Licitações e Contratos https://portal.tcu.gov.br/biblioteca-digital/responsabilizacao-de-agentes-segundo-a-jurisprudencia-do-tcu-uma-abordagem-a-partir-de-licitacoes-e-contratosaulas-1-a-5.htm.

Brasil. (1988). Constituição da República do Brasil de 1988. http://www.planalto.gov.br/ccivil_03/constituicao/constituicao.htm.

Brasil. (2009). Manual do Prefeito. IBAM.

Brasil. (2017). Instrução Normativa n. 05 de 26 de maio de 2017. Dispõe sobre as regras e diretrizes do procedimento de contratação de serviços sob o regime de execução indireta no âmbito da Administração Pública federal direta, autárquica e fundacional. https://www.in.gov.br/materia//asset_publisher/Kujrw0TZC2Mb/content/id/20239255/do1-2017-05-26-instrucao-normativa-n-5-de-26-de-maio-de-2017-20237783.

Brasil. (2021). Lei N ${ }^{o}$ 14.133, de $1^{\circ}$ De Abril De 2021. Lei de Licitações e Contratos Administrativos. https://www.in.gov.br/en/web/dou/-/lei-n-14.133-de-1de-abril-de-2021-311876884.

Carvalho, M. (2021). Manual de Direito Administrativo. Juspodvim.

Dotti, M. (2018). Governança nas contratações públicas: Aplicação Efetiva de Diretrizes, Responsabilidade e Transparência Inter-relação com o direito fundamental à boa administração e o combate à corrupção. Forum.

Enap. (2018). Manual de Gestão e de Fiscalização de Contratos de Serviços Terceirizados da Enap. Portaria/ENAP.

Filho, J. (2012). Manual de Direito Administrativo. Atlas.

Filho, M. Curso de Direito Administrativo. Fórum, 2010.

Gil, A. (2019). Métodos e técnicas de pesquisa social. Atlas.

Junqueira, G. Manual de Prática dos Contratos. Imperium.

Leite, J., Souza, H. \& Nascimento, E. (2010). Contratualização na saúde: proposta de um contrato único para os programas no Estado de Minas Gerais. RAS, 12(46).

Lüdke, M., \& André, M.E.D. A (2013). Pesquisa em Educação: abordagens qualitativas. (2a ed.), EPU

Maximiano, A. \& Nohara, I. (2017). Gestão Pública: Abordagem Integrada da Administração e do Direito Administrativo. Atlas.

Meirelles, H. (1995). Direito Municipal Brasileiro. Malheiros.

Melo, C. (2005). Curso de Direito Administrativo. Malheiros Editores.

Oliveira, R. (2021). Nova Lei de Licitações e Contratos. Forense.

Pietro, M. (2014). Direito Administrativo. Atlas.

Rizzardo, A. (2020). Contratos. Forense. 